\title{
Determination of Capsaicin and Dihydrocapsaicin in Some Chilli Varieties using Accelerated Solvent Extraction Associated with Solid-Phase Extraction Methods and RP-HPLC-Fluorescence
}

\author{
SAKSIT CHANTHAI ${ }^{\mathrm{a}}$, JUREERAT JUANGSAMOOT ${ }^{\mathrm{a}}$, CHALERM \\ RUANGVIRIYACHAI ${ }^{\mathrm{a}}$ and SUCHILA TECHAWONGSTIEN ${ }^{\mathrm{b}}$
}
${ }^{\mathrm{a}}$ Department of Chemistry and Center for Innovation in Chemistry, Faculty of Science, Khon Kaen University, Khon Kaen 40002, Thailand
${ }^{\mathrm{b}}$ Department of Plant Science and Agricultural Resources, Faculty of Agriculture, Khon Kaen University 40002, Thailand
sakcha2@kku.ac.th

Received 10 November 2011; Accepted 16 January 2012

\begin{abstract}
Reversed phase-HPLC with fluorescence detection of two major capsaicinoids was described. Isocratic elution using a ratio of methanol and deionized water $(66: 34, \mathrm{v} / \mathrm{v})$ as mobile phase was used at a flow rate of 0.9 $\mathrm{mL} / \mathrm{min}$ with well achieved separation within 6 min. Under optimum conditions, their analytical figures of merit for the HPLC method were validated. The linearity was in the range of $1.0-25.0 \mu \mathrm{g} / \mathrm{mL}$ with multiple determination coefficients of higher than 0.995 . The limit of detection was ranged of $0.008-0.01 \mu \mathrm{g} / \mathrm{mL}$. The repeatability and reproducibility of the retention time and peak area for these compounds were in good precision with their relative standard deviations (RSDs) lower than $1 \%$ and $5 \%$, respectively. Both capsaicin and dihydrocapsaicin were extracted using an accelerated solvent extraction (ASE) of methanol as an extraction solvent for 5 min static time with 3 cycles. The methanolic extracts were subjected to clean up with $\mathrm{C}_{18}$ solid-phase extraction (SPE) with its recoveries ranking of $90.2-98.0 \%$. The method recoveries of real samples were found to be $60.7-98.6 \%$. The optimized extraction method were applied for the determination of the two capsaicinoids in ten vareities of hot chilli pepper samples. Total contents of capsaicinoids were found in the range of 2,307.0-9047.3 $\mu \mathrm{g} / \mathrm{g}$ DW with their corresponding Scoville heat unit (SHU) of 34,600-135,700. Additionally, the contents of capsaicinoids using external calibration method comparing with those of standard addition were not significantly different, indicating accuracy of the method. Mostly, the contents of capsaicin found in these real samples were rather higher than those of dihydrocapsaicin.
\end{abstract}

Keywords: Capsaicinoids, Capsaicin, Dihydrocapsaicin, Chilli pepper, Accelerated solvent extraction, Fluorescence, RP-HPLC. 


\section{Introduction}

Chilli peppers are generally known as ripen fruits of various species of genus capsicum. They play an important role as one of the most commercial crops used both as condiment or culinary supplement and as vegetable. Generally, their taste is representing a hot sense consisting of capsaicinoids as the major group of organic compounds closely related to the family of alkaloids, and they are known to be biosynthesized and accumulated in the placenta of Capsicum fruits ${ }^{1,2}$. Capsaicin is the major component of capsaicinoids which has been used in neurological research to stimulate sensory nerves and also to treat bladder inflammation. The determination of capsaicinoids in hot peppers, topical cream ${ }^{3}$, selfdefense weapons ${ }^{4}$ and aerosol defense sprays ${ }^{5}$ has been of increasing interest for many reasons. Actually, extraction of capsaicinoids from hot pepper has been conducted using many techniques, including liquid-liquid extraction (LLE) $)^{3,6}$, enzymatic extraction ${ }^{7}$, supercritical fluid extraction $(\mathrm{SFE})^{3,8-11}$, pressurized liquid extraction (PLE) ${ }^{12}$, magnetic stirring extraction $(\mathrm{MSE})^{3}$, solid-phase microextraction $(\mathrm{SPME})^{6}$, reflux ${ }^{13}$, microwave assisted extraction (MAE) $)^{14}$, maceration ${ }^{15}$, Soxhlet extraction ${ }^{16}$, and ultrasonic assisted extraction (UAE) ${ }^{17}$.

Accelerated solvent extraction (ASE) is one of modern techniques which widely implied using organic solvents at high temperature and pressure. ASE can be used under an atmosphere that protects from light. It is rapid, small volume of organic solvent and efficient removal of analytes from various matrices. The ASE extraction can be performed under an inert atmosphere and in the absence of light, which represents a great advantage in the extraction of compounds that may be sensitive to oxidative degradation through the action of the air or the light ${ }^{12}$. Mostly, the extraction is followed by a further sample cleanup step such as solvent/solvent partition, liquid chromatography on aluminium oxide or solid phase extraction. SPE is a method of sample preparation that concentrates and purifies analytes from solution by sorption into a disposable solid phase cartridge ${ }^{17-22}$. After extraction of the capsaicinoids from hot pepper using various organic solvents, analysis was performed by gas chromatography (GC) $)^{5,23}$, high-performance liquid chromatography (HPLC) $)^{12,24,25}$ from which the later is the method of choice to date. Because, HPLC provides advantages over other techniques including high efficiency, short analysis time and low sample consumption. Therefore, the purpose of the present study is aimed to develop a suitable ASE method that is capable of analyzing most capsaicinoids in hot peppers. Previous chromatographic methods have been reported for analytical separation, quantitation and identification of naturally occurring capsaicinoids by HPLC ${ }^{24-36}$, supercritical fluid chromatography (SFC) ${ }^{8}$, thin layer chromatography $(\mathrm{TLC})^{37}, \mathrm{GC}^{5,23}$, capillary electrophoresis $(\mathrm{CE})^{20}$ and spectrophotometry ${ }^{37,38}$.

2003RP-HPLC is currently the most popular and reliable technique for the analysis of capsaicinoids. The technique has been mainly associated with UV absorption detection ${ }^{19-}$ ${ }^{22,37-39}$ or fluorescence detection or photodiode array (PDA) ${ }^{28-31}$ coupled with fluorescence detection $^{11-13,28}$. The recent development of LC-MS provides a useful tool for the determination of these compounds $s^{33,34,38,39}$. But LC-MS is cost effective and its equipment is not common in routine laboratories. Therefore, regarding on practical and reasonable aspects of the analytical methods, the determination of these capsaicinoids in hot chilli peppers using both ASE and SPE methods prior to analysis by HPLC with fluorescence detection was a choice of this study. 


\section{Experimental}

\section{Chemicals}

All reagents used at least analytical reagent (AR) grade such as methanol (Lab Scan, Thailand), ethanol (Carlo Erba, Italy) and acetonitrile (Lab Scan, Thailand). Silica gel (230240 mesh), methanol and acetonitrile were of HPLC grade and obtained from Lab Scan (Thailand). The highest purity of standard capsaicinoids was used. Capsaicin and dihydrocapsaicin were obtained from Sigma (USA). Aqueous solutions were prepared with de-ionized water obtained from $\mathrm{RiOs}^{\mathrm{TM}}$ type 1 simplicity 185 (Millipore Waters, USA) throughout the experiments.

\section{Instruments}

The experiments were carried out on a Waters liquid chromatograph (Waters, USA). It consists of a Waters 600E Multisolvent Delivery System, a Waters In-Line Degasser AF, a Rheodyne injector with sample loop of $20 \mu \mathrm{L}$, a Waters 2475 Multi Wavelength Fluorescence Detector and a Waters Temperature Control System. Empower software was used for data acquisition. A Hypersil ${ }^{\circledR}$ ODS C18 column $(4.6 \mathrm{~mm}$ i.d. $\times 100 \mathrm{~mm}, 3 \mu \mathrm{m}$ particle diameter) was used. An accelerated solvent extractor ASE-200 (Dionex, Sunnyvale, CA, USA) is used for sample extraction. It consists of oven, sample extraction cells, the collection vial volume $(30 \mathrm{~mL})$, needle, solvent reservoir and control panel. The $\mathrm{C}_{18}$ cartridges $(500 \mathrm{mg} / 4 \mathrm{~mL})$ were obtained from Alltech (USA).

\section{Chilli Pepper Samples}

Ten varieties of hot chilli peppers were collected from cultivating sites and seed products Co Ltd. Most of the samples were Capsicum annuum L. (S01, Munpama; S02, Super hot; S05, Yodson, Nonethai-Nakhon Ratchasima; S07, Jinda, Chumsang- Nakhon Sawan; S08, Jinda, Muang-Phetchaboon; S09, Yodson, Theparak-Nakhon Ratchasima; S10, small Jinda), Capsicum chinense L. (S03, Pag-puan; S06, South Africa), and Capsicum frutescens L. (S04, Doi-ded-gan) obtained from Department of Plant Science and Agricultural Resources, Faculty of Agriculture, Khon Kaen University. The dried samples were ground using a kitchen grinder, kept in plastic bag and stored in desiccator before use.

\section{Accelerated Solvent Extraction (ASE)}

Two pieces of Whatman No.42 filter paper (19.8 mm, i.d.) were placed onto cellulose disk $(19.8 \mathrm{~mm}$, i.d.) at the outlet end of the extraction cell. The samples $(2.0 \mathrm{~g})$ and silica gel $(6.0 \mathrm{~g})$ were loaded into the cell and then another filter paper was place again on the top of the sample. The extracts obtained were filtered through the filter paper once, evaporated solvent, diluted in the suitable solvent $5 \mathrm{~mL}$ final volume, and then subjected to clean up by SPE prior to HPLC analysis. The optimum conditions for ASE method were studied in detail using a single variable experimental trial. Thus parameters affecting the extraction yield of capsaicinoids were investigated including solvents (methanol, $80 \%$ ethanol in water and acetonitrile), static time ( $3 \& 5 \mathrm{~min})$, extracting cycle $(3 \& 5$ cycles) and extraction temperature $\left(60,70,80,90,100,150 \& 200^{\circ} \mathrm{C}\right)$. While other conditions of the ASE instrument i.e. pressure $10 \mathrm{MPa}$, heat-up time 5-9 min, flush volume $60 \%$, and purge time 1.5 min were fixed throughout the extraction process. 


\section{Solid-Phase Extraction (SPE)}

The solid-phase cartridge was conditioned with $2 \mathrm{~mL}$ of methanol and followed by $2 \mathrm{~mL}$ of de-ionized water. The extracts obtained $(400 \mu \mathrm{L})$ was diluted with $600 \mu \mathrm{L}$ de-ionized water and subjected into the conditioned cartridge. The capsaicinoids were eluted with $2 \mathrm{~mL}$ methanol twice and adjusted the final volume to $10 \mathrm{~mL}$

\section{Analysis of Capsaicinoids by RP-HPLC-Fluorescence}

For a stock solution of capsaicin $(2,640 \mu \mathrm{g} / \mathrm{mL})$, standard capsaicin was prepared by dissolving of $0.0132 \mathrm{~g}$ in $5.0 \mathrm{~mL}$ of methanol. For dihydrocapsaicin solution $(2,140 \mu \mathrm{g} / \mathrm{mL})$, standard dihydrocapsaicin was also prepared by dissolving of $0.0107 \mathrm{~g}$ in $5.0 \mathrm{~mL}$ of methanol as the same manner. Working solutions were prepared daily by an appropriate dilution in methanol.

\section{Optimization of RP-HPLC Separation}

The optimization for HPLC analysis of capsaicinoids was investigated by varying the composition of mobile phase whereas the other conditions used throughout were as follows: flow rate of $0.9 \mathrm{~mL} / \mathrm{min}$, ambient temperature, and fluorescence detector with excitation wavelength at $278 \mathrm{~nm}$ and emission wavelength at $310 \mathrm{~nm}$. Binary solvent mixtures (50$70 \% \mathrm{v} / \mathrm{v}$ ) of methanol and de-ionized water were used as a mobile phase. The mobile phase was filtered through a $0.45 \mu \mathrm{m}$ nylon membrane and degassed before use. The column was equilibrated with the mobile phase for $30 \mathrm{~min}$ or until a steady detector baseline was achieved.

\section{Method validation of RP-HPLC Separation}

To determine the proposed method provided suitable aspects for quantitative analysis of the capsaicinoids, the following validation data were commonly investigated. To determine the linearity of the HPLC method, a series of standard solution were prepared covering a concentration range of $1.0-25.0 \mu \mathrm{g} / \mathrm{mL}$ by serial dilution of the stock standard solutions for external calibration curve and of $0.5-10.0 \mu \mathrm{g} / \mathrm{mL}$ for standard addition method. The limit of detection (LOD) and limit of quantitation (LOQ) were calculated as the analyte concentration giving a signal to noise ratios $(\mathrm{S} / \mathrm{N})$ of 3 and 10 , respectively using the mixed standard solutions of the capsaicinoids diluted from their stock standard solutions. The precision of the method was presented as the repeatability and reproducibility of retention time and peak area. The repeatability (intra-day precision) was deduced from ten replicates within a day $(n=10)$ and reproducibility (inter-day precision) was calculated from the experiments carried out in three consecutive days $(n=3 \times 5)$. The concentration of mixed standard solutions of the capsaicinoids was $10.0 \mu \mathrm{g} / \mathrm{mL}$.

\section{Results and Discussion}

\section{Optimization of RP-HPLC Separation Conditions and Method Validation}

In this study, the organic solvent selected for the preliminary experiments was methanol $(\mathrm{MeOH})$ due to the solubility of capsaicinoids. The mobile phases containing various percents of methanol in de-ionized (DI) water were investigated. The mobile phase containing $\mathrm{MeOH}$ and DI $(66: 44, \mathrm{v} / \mathrm{v})$ was chosen giving rapid separation of both capsaicin $\left(t_{R} 3.98 \mathrm{~min}\right)$ and dihydrocapsaicin $\left(t_{R} 5.66 \mathrm{~min}\right)$ achieved within 6 min with a 
resolution of 1.2. The quantitative features of the HPLC method were studied under the optimum separation conditions. The linearity was in the range of $1.0-25.0 \mu \mathrm{g} / \mathrm{mL}$. The external calibration curve was plotted between peak area of the capsaicinoid standards and their concentrations. The multiple determination coefficients obtained were higher than 0.995. The regression parameters and multiple determination coefficients of capsaicin $(\mathrm{Y}=$ $\left.1 \times 10^{6} \mathrm{X}-466,226, \mathrm{r}^{2}=0.9985\right)$ and dihydrocapsaicin $\left(\mathrm{Y}=1 \mathrm{x} 10^{6} \mathrm{X}-656,741, \mathrm{r}^{2}=0.9953\right)$ were obtained. Both LOD and LOQ were found to be $0.008-0.01$ and $0.10-0.12 \mu \mathrm{g} / \mathrm{mL}$ for capsaicin and dihydrocapsaicin, respectively. The precision of the method was presented in term of repeatability and reproducibility of retention time and peak area as shown in Table 1. The repeatability and reproducibility of the retention time and peak area for the two capsaicinoids were in good precision with their relative standard deviations (RSD) less than $1 \%$ and $5 \%$, respectively.

Table 1. Repeatability $(n=10)$ and reproducibility $(n=3 \times 5)$ of capsaicinoids analysis by RP-HPLC-fluorescence detection.

\begin{tabular}{|l|c|c|c|c|c|c|c|c|}
\hline \multirow{2}{*}{ Capsaicinoids* } & \multicolumn{5}{|c|}{ Repeatability $(n=10)$} & \multicolumn{3}{c|}{ Reproducibility $(n=3 \times 5)$} \\
\cline { 2 - 9 } & \multicolumn{2}{|c|}{$\mathrm{t}_{\mathrm{R}}(\mathrm{min})$} & \multicolumn{2}{c|}{ Area } & \multicolumn{2}{c|}{$\mathrm{t}_{\mathrm{R}}(\mathrm{min})$} & \multicolumn{2}{c|}{ Area } \\
\cline { 2 - 9 } & mean & $\% \mathrm{RSD}$ & Mean & $\% \mathrm{RSD}$ & mean & $\% \mathrm{RSD}$ & mean & $\% \mathrm{RSD}$ \\
\hline Capsaicin & 3.98 & 0.67 & 15361172 & 3.99 & 3.99 & 0.98 & 15279632 & 4.84 \\
Dihydrocapsaicin & 5.66 & 0.85 & 12616027 & 0.92 & 5.65 & 0.92 & 12655976 & 2.45 \\
\hline
\end{tabular}

\section{Optimization for ASE Conditions and Sample Clean Up}

To optimize the ASE conditions, a combination of increasing temperature and pressure with common solvents to increase the efficiency of the extraction process is performed. ASE offers advantages of a short extraction time and a significant in solvent used. Type of solvent used in the extraction affects the extraction efficiency. Several solvents have been used for the extraction of capsaicinoids. The mostly used organic solvents are methanol, $80 \%$ ethanol in water and acetonitrile. The effect of these solvents on the average extraction efficiency of capsaicinoids from hot pepper samples depends on temperature $\left(60-200^{\circ} \mathrm{C}\right)$, static time $(3$ and $5 \mathrm{~min}$ ) and extraction cycle ( 3 and 5 cycles). Since there are four key parameters involving this extraction procedure including solvent, static time, extraction cycle and temperature, the capsaicinoid contents obtained from various experiments (42 trials) are shown in Table 2 and Fig. 1-3. The extraction yields were found in the ranges of 769.30$3345.3 \mu \mathrm{g} / \mathrm{g}$ DW for capsaicin, 408.80-2428.2 $\mu \mathrm{g} / \mathrm{g}$ DW for dihydrocapsaicin with their RSDs less than $6.0 \%$. High temperature and pressure can modify considerably the physical properties of the extraction solvents, resulting in an increasing of extraction selectivity. Therefore, the method validation of the extraction procedure was also investigated. 
Table 2(a). Contents of capsaicinoids obtained from various conditions of ASE method.

\begin{tabular}{|c|c|c|c|c|c|c|}
\hline \multirow[t]{2}{*}{ No. } & \multirow[t]{2}{*}{ Solvent } & \multirow[t]{2}{*}{ Experiments } & \multicolumn{4}{|c|}{ Contents of capsaicinoids } \\
\hline & & & $\mathrm{C}(\mu \mathrm{g} / \mathrm{g} \mathrm{DW})$ & $\% \mathrm{RSD}$ & $\mathrm{DC}(\mu \mathrm{g} / \mathrm{g} \mathrm{DW})$ & $\% \mathrm{RSD}$ \\
\hline 1 & $\mathrm{MeOH}$ & $60^{\circ} \mathrm{C} / \mathrm{M} 1$ & 1061.6 & 1.38 & 526.7 & 1.51 \\
\hline 2 & & $70^{\circ} \mathrm{C} / \mathrm{M} 1$ & 1539.0 & 0.97 & 709.8 & 3.43 \\
\hline 3 & & $80^{\circ} \mathrm{C} / \mathrm{M} 1$ & 1483.8 & 0.33 & 696.3 & 0.64 \\
\hline 4 & & $90^{\circ} \mathrm{C} / \mathrm{M} 1$ & 2322.6 & 1.27 & 1223.0 & 2.11 \\
\hline 5 & & $100^{\circ} \mathrm{C} / \mathrm{M} 1$ & 1900.3 & 0.09 & 994.4 & 0.44 \\
\hline 6 & & $150^{\circ} \mathrm{C} / \mathrm{M} 1$ & 2741.3 & 0.35 & 1666.7 & 0.24 \\
\hline 7 & & $200^{\circ} \mathrm{C} / \mathrm{M} 1$ & 3345.3 & 3.34 & 2428.2 & 1.40 \\
\hline 8 & & $60^{\circ} \mathrm{C} / \mathrm{M} 2$ & 769.3 & 0.57 & 408.8 & 1.35 \\
\hline 9 & & $70^{\circ} \mathrm{C} / \mathrm{M} 2$ & 1063.3 & 2.02 & 535.8 & 1.64 \\
\hline 10 & & $80^{\circ} \mathrm{C} / \mathrm{M} 2$ & 777.0 & 1.29 & 456.2 & 0.17 \\
\hline 11 & & $90^{\circ} \mathrm{C} / \mathrm{M} 2$ & 1084.5 & 0.85 & 556.2 & 2.09 \\
\hline 12 & & $100^{\circ} \mathrm{C} / \mathrm{M} 2$ & 1211.1 & 2.01 & 614.2 & 3.65 \\
\hline 13 & & $150^{\circ} \mathrm{C} / \mathrm{M} 2$ & 1254.1 & 2.95 & 687.4 & 3.07 \\
\hline 14 & & $200^{\circ} \mathrm{C} / \mathrm{M} 2$ & 2255.0 & 4.01 & 1024.5 & 2.85 \\
\hline
\end{tabular}

Note: M1: 5 min static time, 3 extraction cycles, M2: 3 min static time, 5 extraction cycles.

Table 2(b). Contents of capsaicinoids obtained from various conditions of ASE (cont.).

\begin{tabular}{|c|c|c|c|c|c|c|}
\hline \multirow[t]{2}{*}{ No. } & \multirow[t]{2}{*}{ Solvent } & \multirow[t]{2}{*}{ Experiments } & \multicolumn{3}{|c|}{ Contents of capsaicinoids } & \multirow[b]{2}{*}{$\%$ RSD } \\
\hline & & & $\mathrm{C}(\mu \mathrm{g} / \mathrm{g} \mathrm{DW})$ & $\%$ RSD & $\mathrm{DC}(\mu \mathrm{g} / \mathrm{g} \mathrm{DW})$ & \\
\hline 15 & $80 \% \mathrm{EtOH} / \mathrm{H}_{2} \mathrm{O}$ & $60^{\circ} \mathrm{C} / \mathrm{M} 1$ & 1185.0 & 0.22 & 641.2 & 2.71 \\
\hline 16 & & $70^{\circ} \mathrm{C} / \mathrm{M} 1$ & 1474.1 & 1.04 & 801.1 & 1.41 \\
\hline 17 & & $80^{\circ} \mathrm{C} / \mathrm{M} 1$ & 1185.1 & 0.22 & 641.2 & 2.71 \\
\hline 18 & & $90^{\circ} \mathrm{C} / \mathrm{M} 1$ & 1426.0 & 1.59 & 796.2 & 3.62 \\
\hline 19 & & $100^{\circ} \mathrm{C} / \mathrm{M} 1$ & 1170.9 & 0.61 & 696.3 & 0.79 \\
\hline 20 & & $150^{\circ} \mathrm{C} / \mathrm{M} 1$ & 1676.6 & 0.50 & 963.6 & 1.00 \\
\hline
\end{tabular}


21

22

23

24

25

26

27

28

$200^{\circ} \mathrm{C} / \mathrm{M} 1$
$60^{\circ} \mathrm{C} / \mathrm{M} 2$
$70^{\circ} \mathrm{C} / \mathrm{M} 2$
$80^{\circ} \mathrm{C} / \mathrm{M} 2$
$90^{\circ} \mathrm{C} / \mathrm{M} 2$
$100^{\circ} \mathrm{C} / \mathrm{M} 2$
$150^{\circ} \mathrm{C} / \mathrm{M} 2$
$200^{\circ} \mathrm{C} / \mathrm{M} 2$

$\begin{array}{ll}3091.3 & 0.27 \\ 1670.6 & 0.04 \\ 1257.7 & 0.59 \\ 1600.6 & 0.37 \\ 1830.9 & 1.27 \\ 1372.9 & 1.45 \\ 2194.2 & 0.24 \\ 2991.3 & 0.70\end{array}$

1791.2

0.11

937.8

2.07

690.8

0.32

876.2

1.30

1003.4

1.57

745.3

0.43

1150.1

1.28

1702.1

3.21

Note: M1: 5 min static time, 3 extraction cycles, M2: 3 min static time, 5 extraction cycles.

Table 2(c). Contents of capsaicinoids obtained from various conditions of ASE (cont.).

\begin{tabular}{|c|c|c|c|c|c|c|}
\hline \multirow[t]{2}{*}{ No. } & \multirow[t]{2}{*}{ Solvent } & \multirow[t]{2}{*}{ Experiments } & \multicolumn{3}{|c|}{ Contents of capsaicinoids } & \multirow[b]{2}{*}{$\% \mathrm{RSD}$} \\
\hline & & & $\mathrm{C}(\mu \mathrm{g} / \mathrm{g} \mathrm{DW})$ & $\%$ RSD & $\mathrm{DC}(\mu \mathrm{g} / \mathrm{g} D W)$ & \\
\hline 29 & $\mathrm{ACN}$ & $60^{\circ} \mathrm{C} / \mathrm{M} 1$ & 1096.8 & 0.35 & 598.2 & 0.24 \\
\hline 30 & & $70^{\circ} \mathrm{C} / \mathrm{M} 1$ & 1200.1 & 5.10 & 658.2 & 1.25 \\
\hline 31 & & $80^{\circ} \mathrm{C} / \mathrm{M} 1$ & 2829.6 & 0.68 & 1332.8 & 0.57 \\
\hline 32 & & $90^{\circ} \mathrm{C} / \mathrm{M} 1$ & 1783.6 & 0.66 & 1141.3 & 2.10 \\
\hline 33 & & $100^{\circ} \mathrm{C} / \mathrm{M} 1$ & 907.8 & 2.84 & 520.0 & 1.05 \\
\hline 34 & & $150^{\circ} \mathrm{C} / \mathrm{M} 1$ & 2415.2 & 2.52 & 1235.2 & 2.51 \\
\hline 35 & & $200^{\circ} \mathrm{C} / \mathrm{M} 1$ & 2902.1 & 3.01 & 1925.1 & 0.79 \\
\hline 36 & & $60^{\circ} \mathrm{C} / \mathrm{M} 2$ & 904.0 & 3.18 & 475.0 & 1.96 \\
\hline 37 & & $70^{\circ} \mathrm{C} / \mathrm{M} 2$ & 1021.5 & 5.32 & 602.5 & 2.57 \\
\hline 38 & & $80^{\circ} \mathrm{C} / \mathrm{M} 2$ & 1201.5 & 3.28 & 607.4 & 1.01 \\
\hline 39 & & $90^{\circ} \mathrm{C} / \mathrm{M} 2$ & 987.3 & 0.40 & 511.0 & 0.83 \\
\hline 40 & & $100^{\circ} \mathrm{C} / \mathrm{M} 2$ & 1021.4 & 4.82 & 682.5 & 3.52 \\
\hline 41 & & $150^{\circ} \mathrm{C} / \mathrm{M} 2$ & 1154.8 & 0.45 & 606.4 & 0.24 \\
\hline 42 & & $200^{\circ} \mathrm{C} / \mathrm{M} 2$ & 2931.7 & 0.56 & 1821.9 & 2.05 \\
\hline
\end{tabular}

Note: M1: 5 min static time, 3 extraction cycles, M2: 3 min static time, 5 extraction cycles.

Validation of the extraction method by recovery study was performed. Besides, under the optimization of ASE method (42 extraction trials), it was found that at $200^{\circ} \mathrm{C}, 3 \& 5 \mathrm{~min}$ static time, and $3 \& 5$ cycles associated with SPE clean up gave higher yields. Thus, 12 
extraction trials ( 3 kinds of solvent, $3 \& 5$ min static time, and $3 \& 5$ cycles) were chosen in addition of 2 extraction trials with 1 extraction cycle. The average recoveries for both capsaicin and dihydrocapsaicin in real sample obtained from the 12 extraction trails were rather widely in the ranges of $21.0-81.9 \%$ for capsaicin, and $10.7-88.9 \%$ for dihydrocapsaicin as shown in Fig. 4. The running condition No. 5 and 11 showed poor results. In contrast, the running condition No. 4 gave the highest recoveries for capsaicin $(79.6 \%)$ and dihydrocapsaicin (88.9\%). This condition was then chosen for further studies. The contents of both capsaicinoids found in the real sample used were ranged from 1068.2$3313.6 \mu \mathrm{g} / \mathrm{g}$ DW for capsaicin, 707.50-2009.4 $\mu \mathrm{g} / \mathrm{g}$ DW for dihydrocapsaicin. From above results, number of cycle, static time, temperature and type of solvent could influence both percent yields of capsaicinoids and percent recovery of its extraction method.

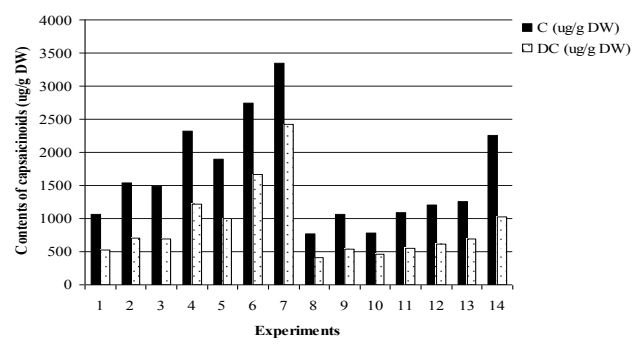

Figure 1. Contents of capsaicinoids obtained from various conditions of ASE using $\mathrm{MeOH}$ as a solvent.

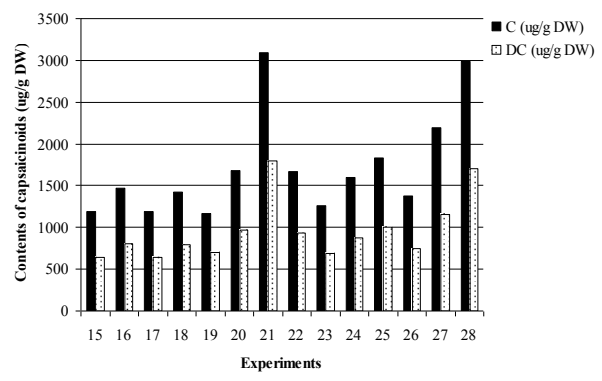

Figure 2. Contents of capsaicinoids obtained from various conditions of ASE using $80 \%$ $\mathrm{EtOH} / \mathrm{H}_{2} \mathrm{O}$ as a solvent.

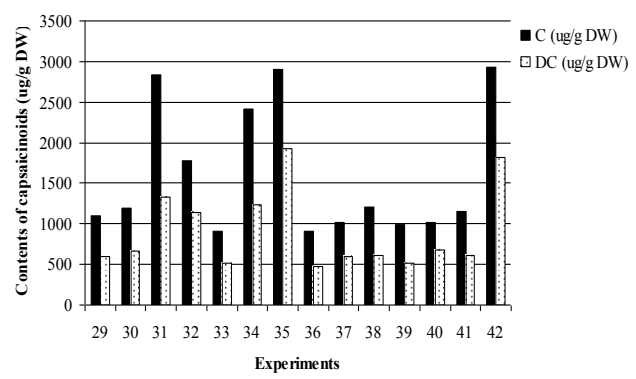

Figure 3. Contents of capsaicinoids obtained from various conditions of ASE using ACN as a solvent. 


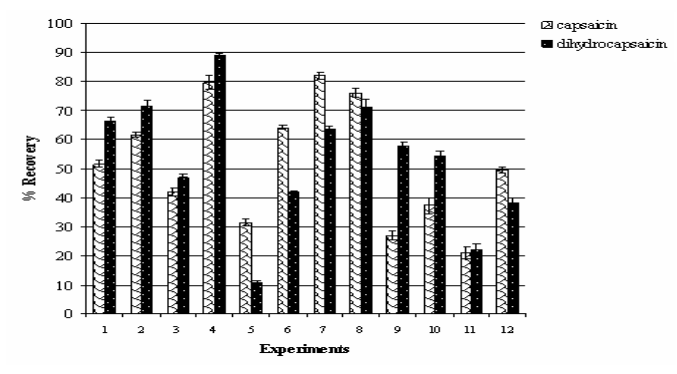

Figure 4. Recovery (\%) of capsaicinoids from 12 experimental trials (mean $\pm \mathrm{SD}, n=3$ ).

However, three choices of each solvent under its optimum extraction conditions could be conducted, resulting in considerably higher in the amounts of both capsaicinoids as shown in Fig. 5. The experimental data as shown above were almost done with clean up using SPE to remove matrices from the analyte prior to HPLC analysis. Recoveries of the SPE for the ASE extracts of both capsaicinoids were found to be 91.8-99.1\% (data not shown).

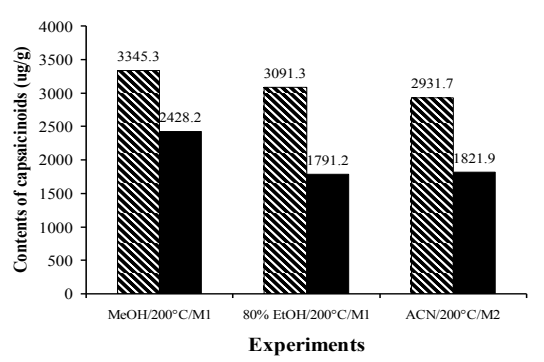

Figure 5. Each of the optimum conditions for ASE of capsaicin and dihydrocapsaicin, where M1: 5 min static time \& 3 extraction cycles; M2: 3 min static time \& 5 extraction cycles.

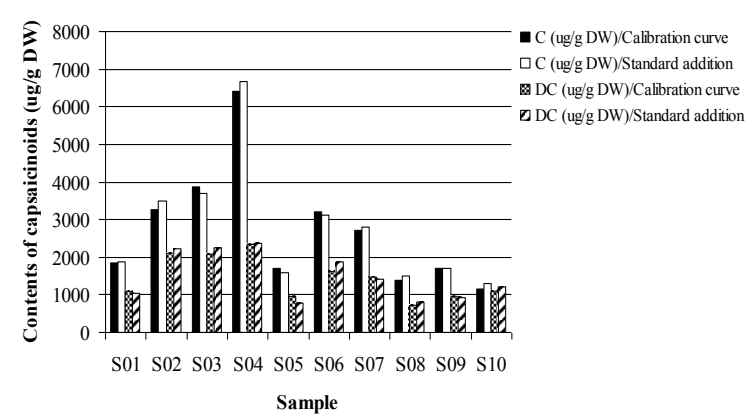

Figure 6. Comparison of contents of capsaicinoids in the samples obtained between calibration curve and standard addition methods.

\section{Analysis of Capsaicinoids in Real Samples}

The extraction and separation method was applied for the determination of capsaicin and dihydrocapsaicin in ten varieties of hot chilli pepper samples using both external calibration 
curve (data not shown) and standard addition methods (Table 3). The contents of capsaicinoids using calibration curve method compared with those of standard addition method showed no significant results as shown in Fig. 6. The contents of capsaicin and dihydrocapsaicin obtained from calibration curve were ranged from 1157.9-6422.1 $\mu \mathrm{g} / \mathrm{g}$ DW and 725.9-2344.8 $\mu \mathrm{g} / \mathrm{g}$ DW, respectively. Sample S04 gave the highest total contents of both capaicinoids $(8766.9 \mu \mathrm{g} / \mathrm{g}$ DW). However, both capsaicin and dihydrocapsaicin have the same trend in contents of the capsaicinoids, and capsaicin was found in higher contents than dihydrocapsaicin in all samples studied. Since standard addition method was proved to reduce interferences in real sample, all samples of the same lot used for external calibration curve were analyzed. It was found that the amounts of capsaicin and dihydrocapsaicin in these samples were also found to be $1295.4-6684.4 \mu \mathrm{g} / \mathrm{g}$ DW and 783.1-2362.9 $\mu \mathrm{g} / \mathrm{g}$ DW, respectively. The total yields of capsaicinoids were ranged of 2307.0-9407.3 $\mu \mathrm{g} / \mathrm{g}$ DW. Table 3 also illustrate the correlation between Scoville heat unit (SHU) and total capsaicinoids obtained. The relationship between the capsaicinoid content $(1 \mu \mathrm{g} / \mathrm{g} \mathrm{DW})$ and its SHU rating was approximately $15 \mathrm{SHU}^{40}$. These data are indicating that both major components of capsaicinoids are primarily responsible for the SHU rating. Thus, the hot chilli pepper sample S04 with high SHU $(135,700)$ will relate with higher contents of capsaicinoids.

Table 3. The contents of capsaicinoids and Scoville heat unit (SHU) determined by standard addition.

\begin{tabular}{|c|c|c|c|c|}
\hline Sample & $\begin{array}{l}\text { Capsaicin } \\
(\mu \mathrm{g} / \mathrm{g} D W)\end{array}$ & $\begin{array}{c}\text { Dihydrocapsaicin } \\
(\mu \mathrm{g} / \mathrm{g} D W)\end{array}$ & $\begin{array}{l}\text { Total capsaicinoids } \\
\qquad(\mu \mathrm{g} / \mathrm{g} D W)\end{array}$ & $\begin{array}{l}\text { Scoville heat unit } \\
\text { (SHU) }\end{array}$ \\
\hline S01 & 1875.0 & 1042.3 & 2917.3 & 43800 \\
\hline S02 & 3494.6 & 2233.4 & 5728.0 & 86000 \\
\hline S03 & 3705.8 & 2246.4 & 5952.1 & 89300 \\
\hline S04 & 6684.4 & 2362.9 & 9047.3 & 135700 \\
\hline S05 & 1598.9 & 783.10 & 2381.9 & 35700 \\
\hline S06 & 3125.0 & 1875.0 & 5000.0 & 75000 \\
\hline S07 & 2815.0 & 1403.2 & 4218.2 & 63300 \\
\hline S08 & 1505.6 & 801.40 & 2307.0 & 34600 \\
\hline S09 & 1698.4 & 920.00 & 2618.4 & 39300 \\
\hline $\mathrm{S} 10$ & 1295.4 & 1208.0 & 2503.4 & 37600 \\
\hline
\end{tabular}




\section{Conclusion}

In the present study, RP-HPLC-fluorescence was used for analysis of major components of capsaicinoids after using ASE method. Under the optimum separating conditions, the limit of detection was ranged of $0.008-0.01 \mu \mathrm{g} / \mathrm{mL}$. The repeatability and reproducibility of the retention time and peak area for the compounds studied were in good precision with their relative standard deviations (RSDs) less than 1\% and 5\%, respectively. Both capsaicin and dihydrocapsaicin were extracted using ASE with the following optimum conditions; methanol as solvent, 5 min static time, 3 extraction cycles followed by clean up with $\mathrm{C}_{18}$ SPE. The method recoveries of these samples were ranged from $69.2-98.6 \%$ and $60.7-94.5 \%$ for capsaicin and dihydrocapsaicin, respectively. The optimized methods were applied for the determination of the two capsaicinoids in ten varieties of hot chilli peppers. Total contents of the capsaicinoids were found in the range of 2,307.0-9047.3 $\mu \mathrm{g} / \mathrm{g} \mathrm{DW}$. The corresponding SHU were also calculated and found in the range of 34,600-135,700 SHU. Mostly, the content of capsaicin found in real sample was higher than that of dihydrocapsaicin.

\section{Acknowledgments}

Research financial supports from both the Center for Innovation in Chemistry (PERCHCIC), Commission on Higher Education, Ministry of Education, Thailand and the Hitachi Scholarship Foundation, Tokyo, Japan are gratefully acknowledged.

\section{References}

1. Pruthi J S, Spices and Condiments, National Book Trust, New Delhi, India, p. 269, 1976.

2. Tapia J C, Garcia R, Eleazar M, Calva G and Rocha J A, Ind. Eng. Chem. Res., 1993, 32, 2242-2246.

3. Kaale E, Schepdael A V, Roets E and Hoogmartens J, J. Pharm. Biomed. Anal., 2002, 30, 1331-1337.

4. Reilly C, Crouch D, Yost G and Fatah A A, J. Chromatogr. A, 2001, 912, 259-267.

5. Spicer O J and Almirall J R, Talanta, 2005, 67, 377-382.

6. Tapia J C, Garcia R, Eleazar M, Calva G and Rocha J A, Indian Engineer. and Chemical Res. 1993, 32, 2242-2246.

7. Santamaria R I, Reyes-Duarte M D, Barzana E, Fernando D, Gama M M and LopezMunguim A, J. Agric. Food Chem., 2000, 48, 3063-3067.

8. Sato K, Sasaki S S, Goda Y, Yamda T, Nunomura O, Ishikawa, K and Maitani T, J. Agric. Food Chem., 1999, 47, 4665-4668.

9. Gnayfeed M H, Daood H G, Illes V and Biacs P A, J. Agric. Food Chem., 2001, 49, 2761-2766.

10. Duarte C, Martins M M, Gouveia A F, da Costa S B, Leitao A E and Gil M G B, J. Superc. Fluids, 2004, 30, 155-161.

11. Uzunalic A P, Skerget M, Weinreich B and Knes Z, Food Chem., 2004, 87, 51-58.

12. Barbero G F, Palma M and Barroso C G, J. Agric. Food Chem., 2006, 54, 3231-3236.

13. Peusch M, Seitz E M, Muller M A and Anklam E, Z. Lebensm. Unters. F. A., 1997, 204, 351-355.

14. Barbero G F, Palma M and Barroso C G, Anal. Chim. Acta, 2006, 578, 227-233.

15. Titze P K, Seitz E M and Petz M, J. Agric. Food Chem., 2002, 50, 1264-1266.

16. Korel F, Bagdatlioglu N, Balaban M O and Hisil Y, J. Agric. Food Chem., 2002, 50, 3257-3261. 
17. Karnka R, Rayanakorn M, Watanesk S and Vaneesorn Y, Anal. Sci., 2002, 18, 661665.

18. Attuquayefio V K and Buckle K A, J. Agric. Food Chem., 1987, 35, 777-779.

19. Betts T A, J. Chem. Educ., 1999, 76, 240-244.

20. Monnerville A L, J. Chromatogr. A, 1999, 838, 293-302.

21. Kim S, Park J B and Hwang K, J. Food Sci., 2002, 67, 2957-2961.

22. Korel F, Bagdatlioglu N, Balaban M O and Hisil Y, J. Agric. Food Chem., 2002, 50, 3257-3261.

23. Thomas B V, Schreiber A A and Weisskop C P, (1998). J. Agric. Food Chem., 1998, 46, 2655-2663.

24. Higashiguchi F, Nakamura H, Hayashi H and Kometani T, J. Agric. Food Chem., 2006, 54, 5948-5953.

25. Schweiggert U, Carle R and Schieber A, Anal. Chim. Acta, 2006, 557, 236-244.

26. Heresch F and Jurenitsch J, Chromatographia, 1979, 12, 647-650.

27. Hoffman P G, Lego M C and Galetto W G, J. Agric. Food Chem., 1983, 31, 13261330.

28. Cooper T H, Guzinski J A and Fisher C, J. Agric. Food Chem., 1991, 39, 2253-2256.

29. Constant H L, Cordell G A, West D P and Johnson J H, J. Nat. Prod., 1995, 58, 19251928.

30. Padilla M C and Yahia E M, J. Agric. Food Chem., 1998, 46, 2075-2079.

31. Estrada B, Bernal M A, Diaz J, Pomar F and Merino F, J. Agric. Food Chem., 2002, 50, 1188-1191.

32. Kurian A L and Starks A N, J. Food Sci., 2002, 67, 956-962.

33. Martin A Ferreres F, Tomas-Barberan F A and Gil M I, J. Agric. Food Chem., 2004, 52, 3861-3869.

34. Kozukue N, Han J S, Kozukue E, Lee S J, Kim J A, Lee K R, Lewin C E and Friedman M, J. Agric. Food Chem., 2005, 53, 9172-9181.

35. Materska M and Perucka I, J. Agric. Food Chem., 2005, 53, 1750-1756.

36. Thomson R, Phinney K, Sander L and Welch M, Anal. Bioanal. Chem., 2005, 381, 1432-1440.

37. Bajaj K L and Kaur G, Mikrochim. Acta, 1979, I, 81-86.

38. Perucka I and Oleszek W, Food Chem., 2000, 71, 287-291.

39. Lui X, Ardo S, Bunning M, Parry J, Zhou K, Stushnoff C, Stoniker F, Yu L and Kendall P, LWT-Food Sci. Technol., 2007, 40, 552-557.

40. Mathur R, Dangi R S, Dass S C and Malhotra R C, Curr. Sci., 2000, 79, 278-288. 


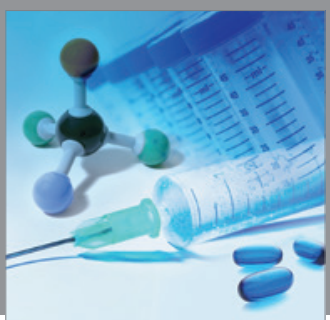

International Journal of

Medicinal Chemistry

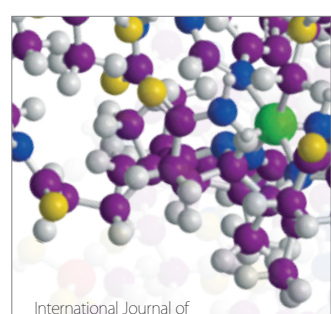

Carbohydrate Chemistry

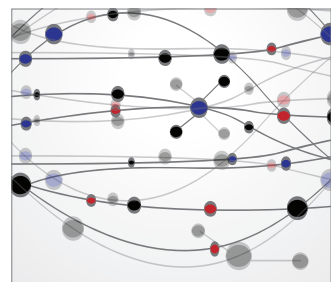

The Scientific World Journal
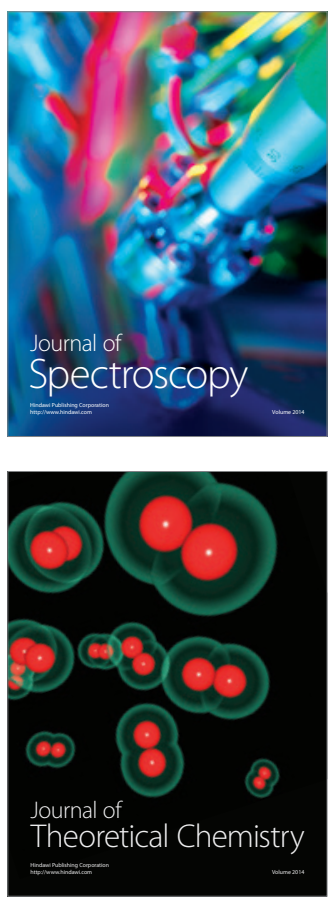
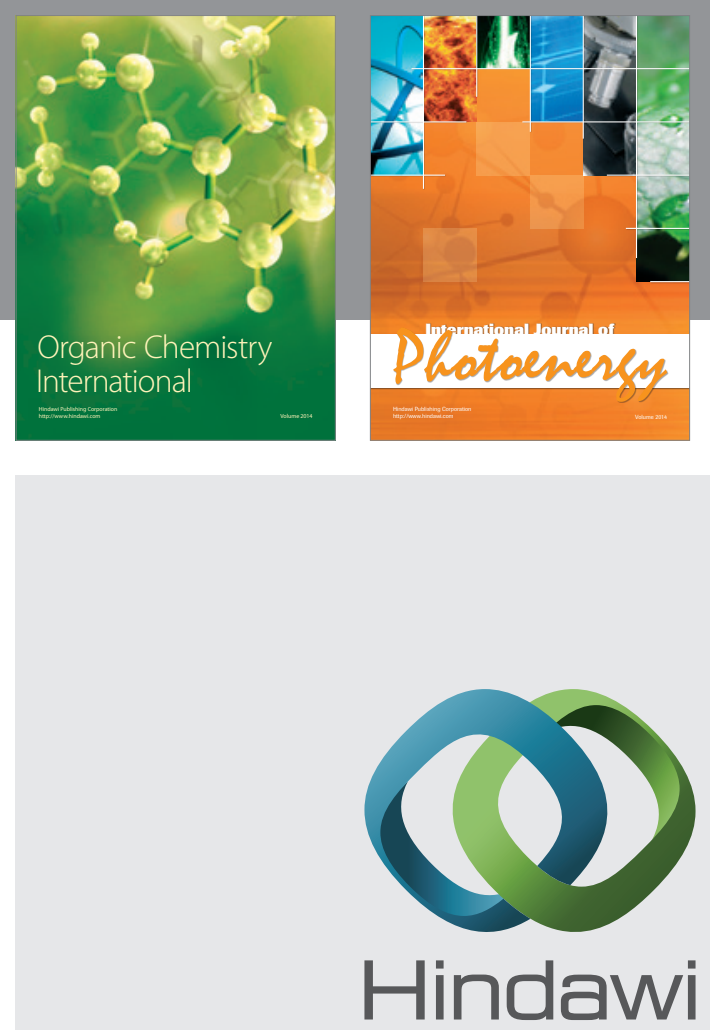

Submit your manuscripts at

http://www.hindawi.com
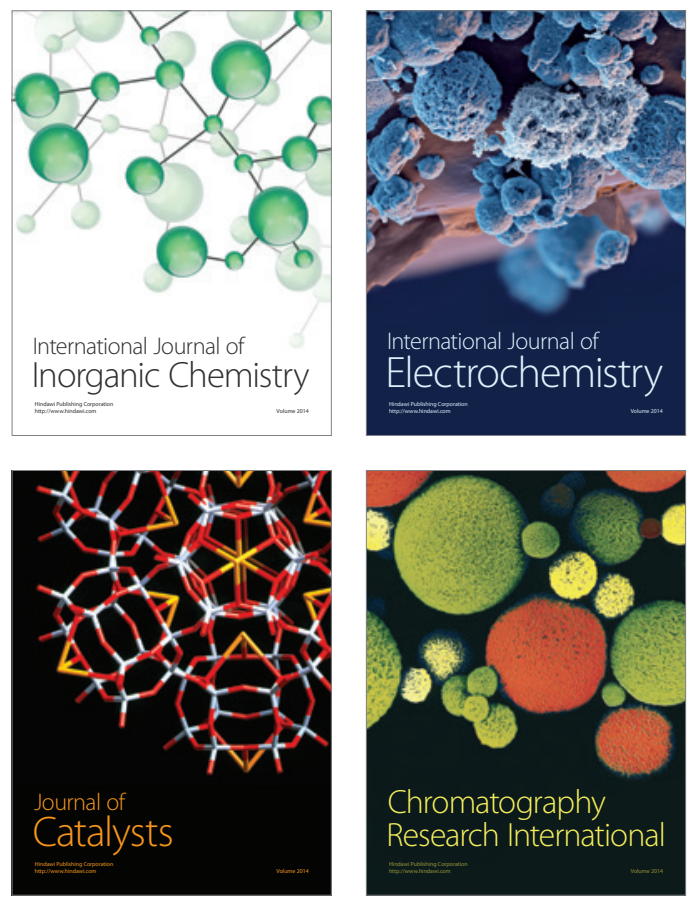
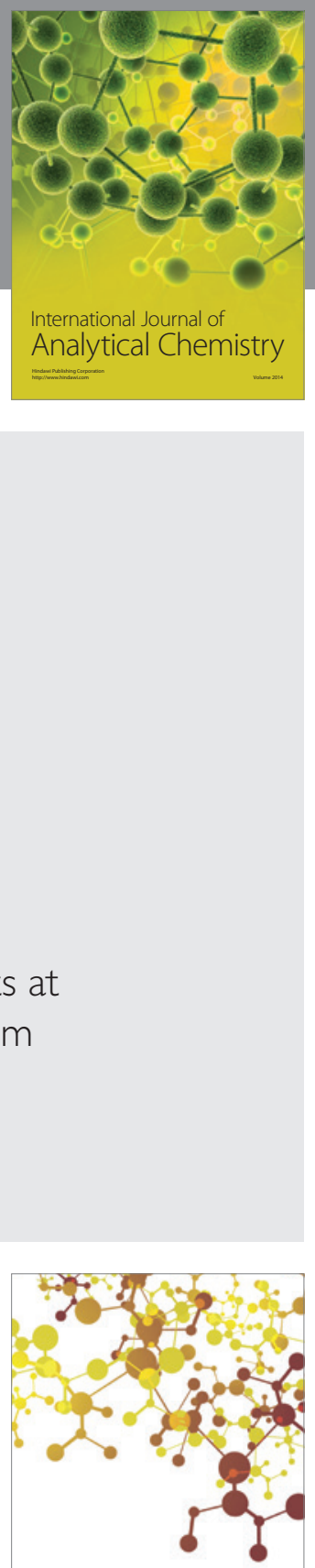

Journal of

Applied Chemistry
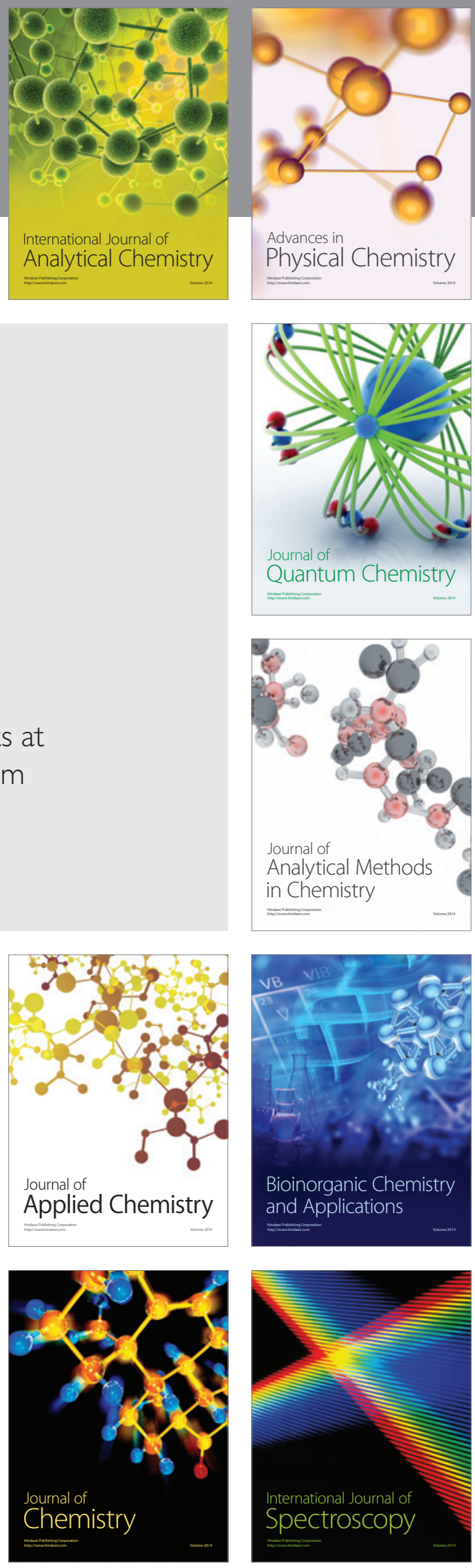